\title{
Use of Bovine Milk Concentrate Containing Antibody to Rotavirus to Treat Rotavirus Gastroenteritis in Infants
}

\author{
Helmut Hilpert, Harald Brüssow, Carl Mietens, \\ Josette Sidoti, Lothar Lerner, and Hermann Werchau
}

\author{
From the Nestle Research Center, NESTEC Limited, \\ Verschez-les-Blanc, Lausanne, Switzerland; and the \\ Universitätskinderklinik, St. Josef-Hospital, and the Institute \\ of Medical Microbiology and Virology, Ruhr-Universität, \\ Bochum, Federal Republic of Germany
}

\begin{abstract}
The use of a concentrate containing milk immunoglobulins prepared from rotavirushyperimmunized cows (neutralization titer, 1:6,000 for a 10\% solution) to treat infants hospitalized for acute rotavirus gastroenteritis resulted in a significant $(P=.008)$ reduction in the duration of excretion of virus. Stool samples from treated infants showed the presence of bovine milk immunoglobulins in $47 \%$ of cases and of neutralizing activity in $43 \%$ (mean neutralization titer, 1:48); stool samples from control infants showed neutralizing activities in only $3 \%$ of cases (neutralization titers, $<1: 20$ ). Immunoelectrophoresis of stool extracts revealed fragment $A$, a bovine analogue of $F(a b)_{2}$ or Fab, as the major product of in vitro and in vivo digestion of the immunoglobulins. Cessation of excretion of virus correlated with the appearance of neutralizing activities in 19 of 25 infants. Only concentrate-treated infants with high neutralizing activity in stools showed a statistically significant reduction in duration of excretion of virus; this duration in concentrate-treated infants with low neutralizing activity was comparable with controls.
\end{abstract}

Rotaviruses were first recognized in 1973 as a cause of nonbacterial infectious gastroenteritis in infants [1]. Epidemiological studies have shown that rotaviruses are found in $40 \%-50 \%$ of infants with gastroenteritis who were admitted to hospitals during the cold season [2-4]. The highest incidence of rotavirus infection has been observed in children six months to two years of age $[2,3,5]$.

Active immunization as an appropriate immunoprophylaxis against infection is the subject of intensive research [6-8], and encouraging results have

Received for publication 21 April 1986, and in revised form 23 January 1987.

This publication is dedicated to the late Professor P. Bachmann (Institute for Medical Microbiology, University of Munich, Munich), whose help and advice were essential for accomplishing this work.

Parents were informed of the aims of the study, and written consent was obtained for all treated infants. The protocol of the study had previously been approved by the ethics committee of the Faculty of Medicine, Ruhr-Universität, Bochum.

We thank Dr. J. Sotek (Mathematics Section), Nestlé Research Department, for statistical analysis; R. Wigger and the nursing staff of the Universitätkinderklinik, Bochum, and K. Sure, Institute for Medical Microbiology, Ruhr-Universität, Bochum, for assistance; Dr. I. Horman for assistance with English; and C. Isom for typing the manuscript.

Please address requests for reprints to Dr. H. Hilpert, Immunology Section, Nestlé Research Department, NESTEC Limited, Avenue Nestlé 55, CH-1800 Vevey, Switzerland. been obtained with a bovine rotavirus vaccine $[9,10]$. Nevertheless, because of problems arising from the practicability of actively immunizing young infants and from treating diarrheal disease caused by rotavirus infections in hospitalized infants, passive immunization also remains of major importance.

Animal studies [11-17] suggest that orally administering virus-neutralizing milk and blood serum antibodies provides local, passive immune protection against experimental rotavirus infection. Clinical studies to investigate whether breast-fed infants suffer less diarrhea than do formula-fed infants have given contradictory results, as reviewed by Cushing and Anderson [18]. Both breast-fed and bottle-fed infants develop rotavirus diarrhea [19]. In some studies $[20,21]$, breast-fed infants were observed to excrete rotavirus significantly less frequently and in lower titers than did formula-fed infants. In a longitudinal study in northern Canada [22], however, breast-feeding appeared to offer no protection from either rotavirus infection or symptomatic illness.

Two studies on passive immune prophylaxis of rotavirus gastroenteritis in human infants have been carried out. Barnes et al. [23] reported favorable results in a prevention trial with gamma-globulin from human blood serum orally administered to infants of low birth weight. Ebina et al. [24, 25] fed lyophilized, skimmed colostral milk from rotavirusimmunized cows to infants. Although the number 
of infants tested was small, prevention of rotavirus gastroenteritis seemed to be possible, although the treatment was unsuccessful.

In earlier publications $[26,27]$ we described the preparation of a concentrate of immunoglobulins isolated from the milk of Escherichia coli-immunized milking cows and the promising use of this concentrate for treating infantile gastroenteritis caused by enteropathogenic $E$. coli. Here we report on a bovine milk concentrate containing antibody to human rotavirus and on its efficiency in treating infantile rotavirus gastroenteritis.

\section{Subjects and Methods}

Milk immunoglobulin concentrate. The preparation and antiviral activity of concentrate samples $A, B$, and $C$ is described in detail elsewhere [28]. In brief, the concentrate was prepared from cow's milk by removing milk fat, casein, lactose, and mineral salts. The milk was then sterile filtered, and the resulting whey protein solution was freeze dried. Concentrate A (neutralization titer of $10 \%$ solution, 1:330) was isolated from mixed colostral milk (first and second milking after calving) from at least five nonimmunized cows. Concentrate $B$ (neutralization titer of $10 \%$ solution, $1: 1,100$ ) was isolated from the mixed milk of $\mathbf{4 0}$ lactation days after calving from rotavirus-hyperimmunized cows. Concentrate $\mathrm{C}$ (neutralization titer of $10 \%$ solution, 1:6,000) was prepared from the mixed milk of only 10 lactation days after calving from at least four rotavirushyperimmunized cows.

Stool samples. Stools were frozen within $2 \mathrm{hr}$ after defecation and kept at $-20 \mathrm{C}$. Extracts were prepared by using $10 \mathrm{ml}$ of ice-cold PBS (pH 7.2)/g of stool. Stool extracts were clarified by centrifugation $(10,000 \mathrm{~g}$ for $20 \mathrm{~min}$ at $0 \mathrm{C})$.

Neutralization test. A series of twofold dilutions, starting with a $1: 5$ dilution, of stool extracts $(10 \%$ stool suspension in PBS), was used for neutralization tests, according to Gerna et al. [29]. Bovine rotavirus V1005 [30, 31], human rotavirus Wa (serotype 1) [32], and simian rotavirus SA-11 [32] were used to measure rotavirus-neutralizing activity.

In vitro proteolysis. At enzyme: substrate ratios of $1: 150,1: 30$, and $1: 6$, solutions of $1 \mathrm{mg}$ of concentrate $/ \mathrm{ml}$ were subjected to in vitro proteolysis by pep$\sin$ (Sigma, St. Louis) at pH $2(0.05 \mathrm{M} \mathrm{KCl}$ and 0.001 $M \mathrm{HCl}$ buffer), pH 3 (0.05 $M$ glycine and $0.001 M$ $\mathrm{HCl}$ buffer), and $\mathrm{pH} 4$ (0.07 $M$ sodium acetate) and by trypsin (Serva, Heidelberg, FRG) at pH 8.0 (0.05 $M$ Tris-HCl and $0.01 M_{C^{2}}$ ) for 2 hr at 37 C. Pepsin was inactivated by using $10 \% \mathrm{Na}_{2} \mathrm{CO}_{3}$ to raise the $\mathrm{pH}$ to 8.0. Trypsin was inactivated by adding soybean trypsin inhibitor (Serva).

Immunodiffusion techniques. Double immunodiffusion tests were performed according to the methods of Ouchterlony [33]. Immunoelectrophoresis was carried out as described by Scheidegger [34]. Agarose gels for both techniques were poured on Gelbond Film (LKB-Produkter AB, Bromma, Sweden). Freeze-dried rabbit antibody to bovine IgG1 (gift from J. J. Pahud, Nestlé, Lausanne) was used in a 1:5 dilution for both techniques. Fecal extracts were used undiluted.

Clinical studies. One hundred sixty-four infants up to two years of age who had been admitted to the University Children's Hospital at Bochum with acute gastroenteritis were included in this study. All infants had been fed a commercial milk formula before the onset of the disease.

To detect the causative agents of gastroenteritis (rotavirus, enteropathogenic bacteria), we took two stool samples as soon as possible after hospital admission and before treatment was started. Infants who were positive for rotavirus and negative for enteropathogenic bacteria in stools and for whom parental written, informed consent was obtained were included in the treatment group; untreated infants hospitalized during the same period who were positive for rotavirus and negative for enteropathogenic bacteria in stools were included in the control group. The assignment of infants to either the treatment or control group depended only on whether parenteral consent could be obtained before or immediately after two stools were passed. Sometimes the purpose and conditions of the study could not be explained to the parents in time, and some parents were opposed to any experimental treatment.

In both groups, stools were examined daily for rotavirus up to the 12 th day after admission or until at least two consecutive negative samples were detected in the same patient. Only those infants with two consecutive stool samples positive for rotavirus after hospitalization were included in the study.

Diarrhea was clinically defined as the passing of liquid or watery stools and was linked with failure to thrive, loss of weight, and, possibly, vomiting.

Except for the administration of concentrate, treatment of diarrhea was identical in both groups and consisted of oral or parenteral rehydration, a di- 


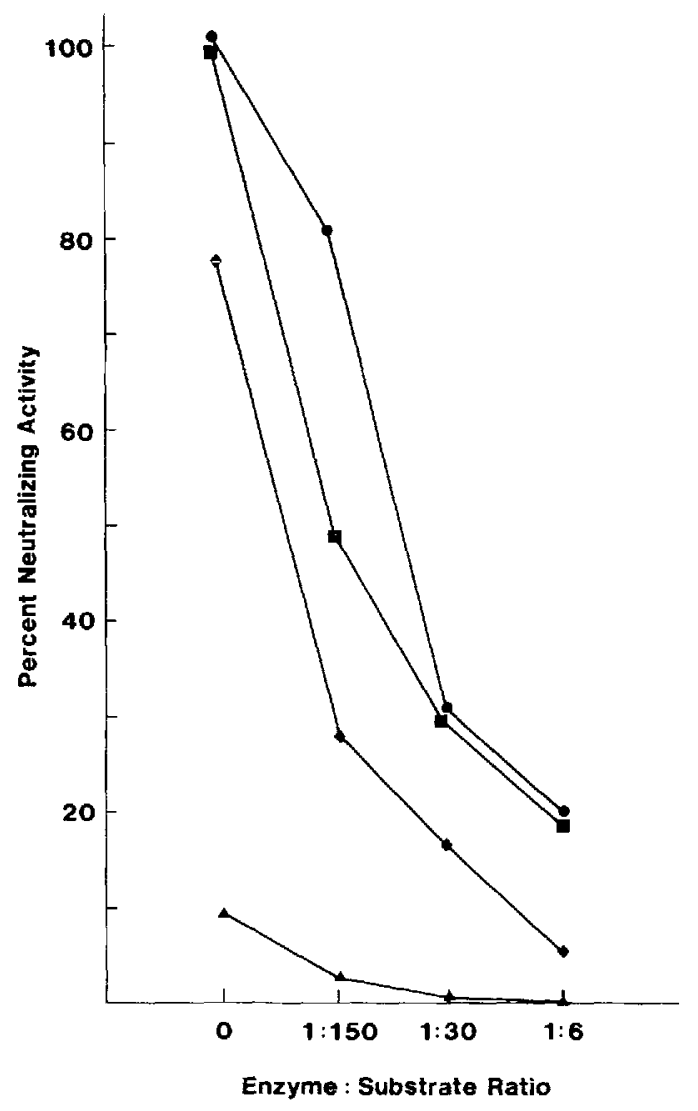

Figure 1. In vitro digestion of the milk immunoglobulin concentrate. The concentrate was digested with tryp$\sin$ at pH $8(\bullet)$ and with pepsin at pH $2(\Delta), 3(\bullet)$, and $4(\boldsymbol{D})$ at the indicated enzyme:substrate ratio. The percentage of neutralizing activity of the digested concentrate (mean of triplicate determinations) is plotted on the ordinate.

etary regimen with cooked-carrot preparations on the first day, and a stepwise reintroduction of a commercial infant formula. In the treatment group, the concentrate containing antibody to rotavirus (A, B, or C) was added to the indicated dietary regimen at a daily dosage of $2 \mathrm{~g}$ of concentrate $/ \mathrm{kg}$ of body weight per day for five days. The administration of the concentrate was distributed equally over all meals and started, on average, on the second day of hospitalization. Infants were not treated on the first day of hospitalization because we were concerned that the initial detection of rotavirus might be masked by coating the rotavirus particles with bovine antibodies to rotavirus. Further, it took some time to obtain parental consent.

Detecting rotavirus. A commercial ELISA test kit (Rotazyme ${ }^{\circledR}$; Abbott, Diagnostic Products, Wiesbaden, FRG) was used to detect rotavirus. Indications from the supplier that $5 \times 10^{6}$ rotavirus particles $/ \mathrm{ml}$ could be detected were confirmed experimentally. Furthermore, we determined that in a range from $5 \times 10^{6}$ to $5 \times 10^{8}$ particles $/ \mathrm{ml}$, the optical density read in the ELISA was proportional to the particle concentration.

To exclude false-negative results due to the coating of rotavirus particles with bovine antibodies, we independently tested stool samples taken in the critical transition period from positive to negative ELISA for the presence of rotaviruses by RNA gel electrophoresis or by electron microscopy or by both techniques.

\section{Results}

In vitro proteolysis. Fifty percent of the antiviral activity of the concentrates was recovered after exposing them to pepsin at an enzyme:substrate ratio of 1:150 at $\mathrm{pH} 4$. Thirty percent recovery was observed at a ratio of $1: 30$. About $20 \%$ of the activity was recovered at $\mathrm{pH} 3$, with ratios of 1:150 and 1:30. No activity was recovered after exposing the concentrates to pepsin at $\mathrm{pH} 2$ (figure 1). Trypsin had nearly no effect on the biologic activity at an enzyme:substrate ratio of $1: 150$ but reduced the activity to $30 \%$ and $20 \%$ at higher enzyme:substrate ratios (figure 1). Fragment $\mathrm{A}$, a bovine analogue of

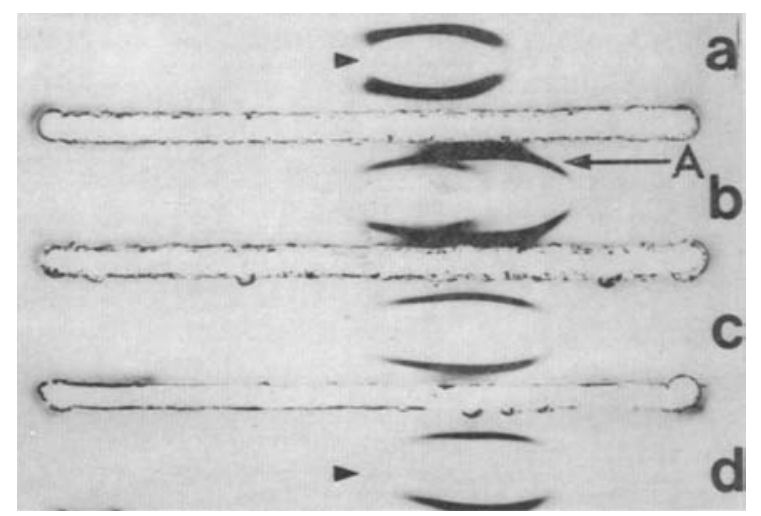

Figure 2. Immunoelectrophoresis of in vitro digestion of the milk immunoglobulin concentrate. $a$, Control concentrate; $b$, concentrate digested with pepsin (1:150) at $\mathrm{pH}$ 4 ; $c$, concentrate digested with pepsin $(1: 150)$ at $\mathrm{pH} 3 ; d$, concentrate digested with pepsin $(1: 30)$ at $\mathrm{pH} 3, A$, fragment A; and arrowhead, position of center well. The anode is on the left. 
$F\left(a b^{\prime}\right)_{2}$ or Fab $[35,36]$ and intact IgG were revealed by immunoelectrophoresis of the concentrates after mild pepsin digestion. Fifty percent of the antiviral activity survived these conditions (figure $2 b$ ). Only fragment $A$ was detected after pepsin treatment, which reduced the neutralizing activity to $25 \%$ or $15 \%$ (figure 2, $c$ and $d$ ).

In vivo proteolysis. A dosage of $2 \mathrm{~g}$ of concentrate $\mathrm{B} / \mathrm{kg}$ of body weight per day was given to infants for five days. About half of the stool samples from concentrate-treated infants contained bovine milk antibodies exhibiting complete or partial identity with native bovine milk immunoglobulins in the Ouchterlony test (figure 3). No bovine immunoglobulins were detected in the stools of control infants. Immunoelectrophoresis revealed intact IgG1, fraginent $A$ (bovine analogue of $F\left(a^{\prime}\right)_{2}$ or $F a b[35,36]$ ), fragment $B$ (bovine analogue of $\mathrm{Fc}[35,36]$ ), and fragment $C$ (bovine analogue of $\mathrm{Fc}^{\prime}[35,36]$ ). The patterns varied for different infants (figure 4).

Antiviral activity. Daily stool samples were taken from concentrate-treated and control infants after hospitalization for rotavirus gastroenteritis. Two random stool samples from each of 55 control infants and from each of 22 infants treated with concentrate B (neutralization titer, 1:1,100) were checked for the presence of bovine milk immunoglobulins by the Ouchterlony test and for neutralizing activity against bovine rotavirus V1005, which is serologically unrelated to human rotavirus [31]. Concentrate B-treated infants had bovine immunoglobulins in $21(48 \%)$ of the 44 stool samples examined and in $11(25 \%)$ stool samples, neutralizing activities, with a mean neutralization titer of $1: 8$ (mean of neutralizing stool samples only). Bovine immunoglobulins were, however, undetectable in 110 stool samples from control infants; only three $(3 \%)$ of these stool

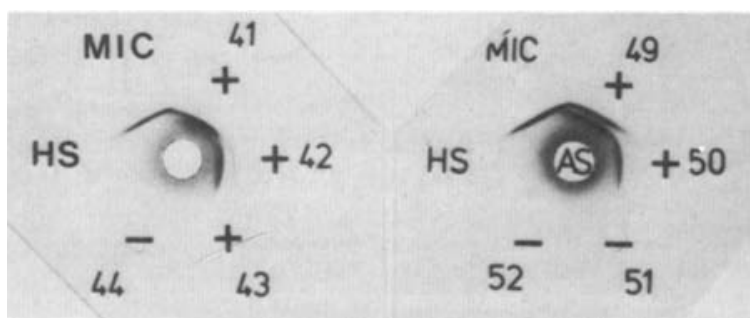

Figure 3. Immunodiffusion test (Ouchterlony) of stool extracts. +, Concentrate-treated infants; - , control infants; $A S$, rabbit antiserum to bovine $\mathrm{IgGl} ; M I C, 1 \mathrm{mg}$ of milk immunoglobulin concentrate/ml; and $H S$, human serum diluted 1:200.

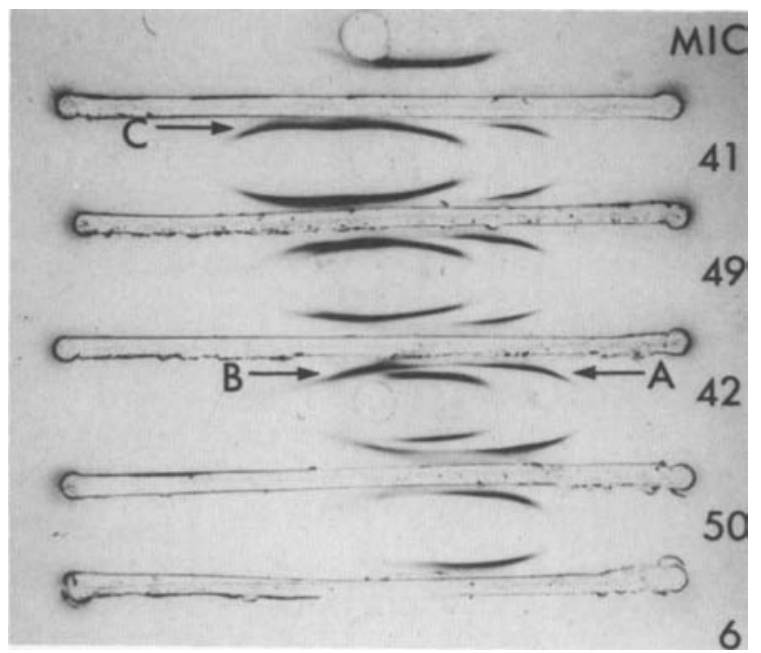

Figure 4. Immunoelectrophoresis of stool extracts. Antigen wells $41,49,42$, and 50 , from concentrate-treated infants; well 6 , from a control infant; antiserum troughs, rabbit antiserum to bovine $\operatorname{IgGl} ; A, B$, and $C$, fragments $\mathrm{A}, \mathrm{B}$, and $\mathrm{C}$ of bovine IgGl; and $M I C, 1 \mathrm{mg}$ of control concentrate $/ \mathrm{ml}$. The anode is on the left.

samples showed neutralizing activity against bovine rotavirus V1005.

Three hundred four stool samples from 43 infants treated with the high-titered concentrate $C$ preparation (neutralization titer, 1:6,000) were studied, including stool samples taken before and after treatment. One hundred forty-two $(47 \%)$ samples had bovine immunoglobulins and $132(43 \%)$ samples, rotavirus V1005-neutralizing activities, with a mean neutralization titer of 1:48 (mean for neutralizing stool samples only). There was a nearly perfect correlation between the presence of bovine IgG1, as shown by the immunodiffusion technique, and neutralizing activity. One hundred twenty-two stool samples had both bovine IgG1 and neutralizing activity, 12 had neutralizing activity without detectable IgG1 (3.9\%, as in control infants, see above), and $19 \mathrm{had}$ IgG1 but were not neutralizing. All but six of the 43 infants treated with concentrate $C$ had at least two neutralizing stool samples. From the known amount of concentrate ingested by infants and the measured neutralizing activity in the stool samples, we estimated that $\sim 10 \%$ of the orally administered antiviral activity was recovered from stools after gastrointestinal passage.

Figure 5 shows the parallel appearance of bovine immunoglobulins and virus-neutralizing activity in stool samples from 43 infants treated with concen- 

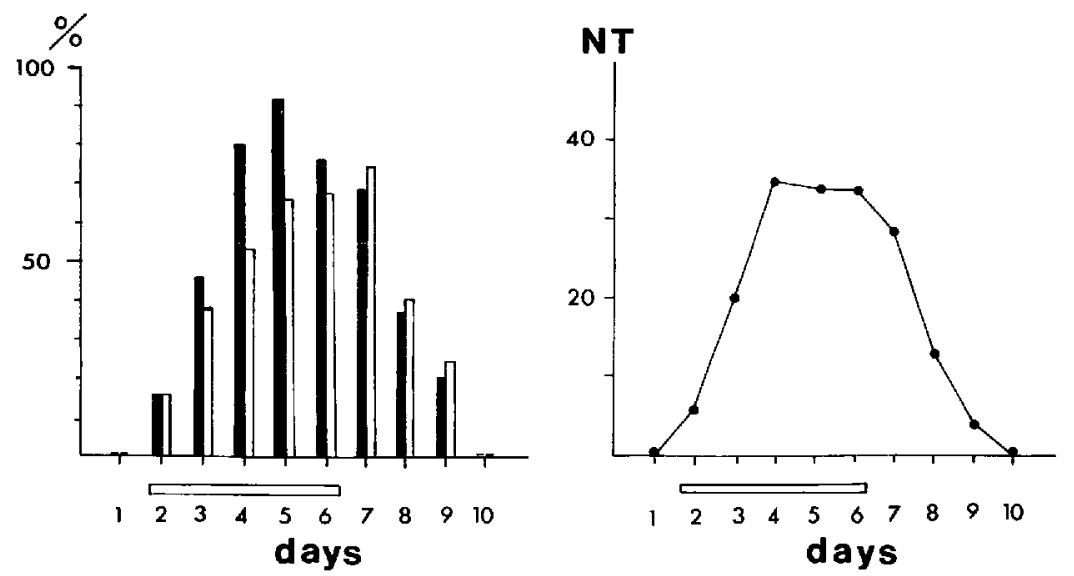

Figure 5. Left, the appearance of bovine immunoglobulins (black bars) and virus-neutralizing activity (white bars) in stool samples from concentrate $\mathrm{C}$-treated infants. The treatment period is indicated by a horizontal white bar. Right, the mean neutralization titer (NT) of stool samples from all concentrate $\mathrm{C}$-treated infants in relation to the treatment period.

trate C. From the third treatment day until one day after cessation of treatment, $79 \%$ of all stool samples were positive for bovine IgG1, and $65 \%$ neutralized bovine rotavirus V1005, with a mean neutralization titer of 1:34 for all stool samples (negative stools included). Ninety-four percent and $67 \%$ of the stool samples that neutralized bovine rotavirus V1005 also neutralized simian rotavirus SA-11 and human rotavirus Wa, respectively. An analysis of stool samples from individual patients revealed that, on average, infants excreted nonneutralizing stool samples for 1.6 days after the start of treatment, whereas neutralizing stool samples were still observed, on average, 1.5 days after the end of treatment. From these figures, we estimated that it took $\sim 1.5$ days for the concentrates to pass through an infant's digestive tract. Cessation of excretion of virus correlated with the appearance of neutralizing activity in $19(75 \%)$ of 25 analyzed infants (representative example is shown in figure 6A), although this kinetic correlation did not prove a causal relationship. In six $(25 \%)$ of 25 infants, rotavirus was still excreted, despite the presence of neutralizing activity (representative example is shown in figure 6B).

Treatment of gastroenteritis. Hospitalized children suffering from rotavirus diarrhea were treated over three consecutive years with three different milk immunoglobulin concentrates. In the first trial (winter of 1982-1983), infants were given concentrate A, which had a mean neutralization titer of 1:330 (for a $10 \%$ solution) against the four human rotavirus serotypes. No significant positive effects were seen in treated infants when compared with control infants (table 1). Concentrate B, with a mean neutraliz-
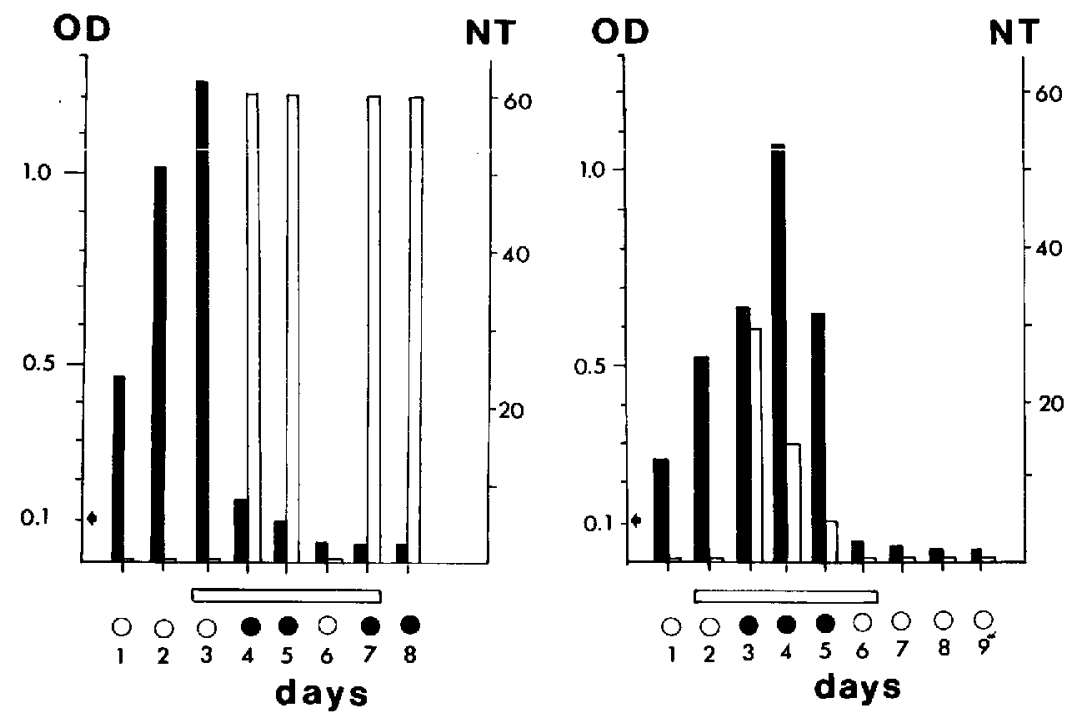

Figure 6. Excretion of virus measured as optical density $(O D)$ in an ELISA (black bars) and virusneutralizing activity (white bars) indicated by the neutralization titer $(N T)$ in stool samples from two concentrate C-treated infants. The treatment period is indicated by the white horizontal bar. - Stool samples containing bovine IgG; and arrow, cutoff point for rotavirus-positive ELISA values. 
Table 1. Treatment of rotavirus gastroenteritis with a bovine milk concentrate containing antibody to rotavirus.

\begin{tabular}{|c|c|c|c|c|c|c|}
\hline \multirow[b]{3}{*}{ Study period } & \multirow[b]{3}{*}{ Treatment* } & \multirow[b]{3}{*}{ No. of infants } & \multicolumn{4}{|c|}{ Duration (days) of event after hospitalization } \\
\hline & & & \multicolumn{2}{|c|}{ Diarrhea } & \multicolumn{2}{|c|}{ Excretion of virus } \\
\hline & & & Mean $\pm S E$ & $\boldsymbol{P}$ & Mean \pm SE & $P$ \\
\hline \multirow[b]{2}{*}{$1982-1983$} & None & 22 & $2.73 \pm 0.43$ & \multirow[b]{2}{*}{.16} & $3.91 \pm 0.51)$ & \multirow[b]{2}{*}{.75} \\
\hline & Concentrate A & 23 & $3.52 \pm 0.42\}$ & & $4.04 \pm 0.35\}$ & \\
\hline \multirow{2}{*}{$1983-1984$} & None & 24 & $2.29 \pm 0.39)$ & \multirow[b]{2}{*}{.58} & $3.58 \pm 0.48$ & \multirow[b]{2}{*}{.31} \\
\hline & Concentrate B & 22 & $2.59 \pm 0.36\}$ & & $4.23 \pm 0.39$ & \\
\hline \multirow[b]{2}{*}{$1984-1986$} & None & 43 & $3.36 \pm 0.33)$ & \multirow[b]{2}{*}{.349} & $5.02 \pm 0.29$ & \multirow[b]{2}{*}{.008} \\
\hline & Concentrate $\mathrm{C}$ & 30 & $2.93 \pm 0.25\}$ & & $3.87 \pm 0.28\}$ & \\
\hline
\end{tabular}

NOTE. The $P$ values are based on the Ancova test with the covariable duration of diarrhea before hospitalization.

* Two grams of concentrate $/ \mathrm{kg}$ of body weight per day was mixed into an appropriate dietary regimen; treatment started on the second day of hospitalization.

ing titer of 1:1,100 (for a 10\% solution) against human rotaviruses, was administered to children in a second clinical trial (winter of 1983-1984). Again, no difference was detected between treated and control infants (table 1).

In a third clinical trial (winters of 1984-1985 and 1985-1986), infants were treated with concentrate $C$, with a mean neutralizing titer of $1: 6,000$ (for a $10 \%$ solution) against human rotaviruses. This treatment resulted in a decrease in the duration of excretion of virus after hospitalization; the mean was 5.02 days in control infants and 3.87 days in treated infants $(P=.008)$. Although a decease in the duration of diarrhea was observed ( 2.93 days in treated infants vs. 3.36 days in controls), this difference was not statistically significant (table 1 ).

The clinical results correlated with the recovery of antiviral activity from the stools. Infants treated ineffectively with concentrate B (neutralization titer,
$1: 1,100$ ) had neutralizing activity in only $25 \%$ of the stool samples, with a mean titer of 1:8. Infants treated successfully with concentrate $\mathbf{C}$ (neutralization titer, 1:6,000) showed neutralizing activity in $43 \%$ of the stool samples, with a mean titer of 1:48. The strongest evidence for an effect was that a close relationship was also found within the concentrate C-treated group. Only infants with high levels of neutralizing activity in stools (two or more stool samples with neutralization titers $\geqslant 1: 20$ ) showed a clinical effect, compared with control infants ( 3.36 days vs. 5.02 days for the duration of excretion of virus and 2.54 days vs. 3.36 days for the duration of diarrhea; table 2). Infants with low levels of neutralizing activity in their stools were, however, clinically indistinguishable from control infants ( 5.00 days vs. 5.02 days for excretion of virus and $\mathbf{3 . 1 3}$ days vs. 3.36 days for diarrhea; table 2).

To ensure that patient randomization into the con-

Table 2. Clinical response of concentrate $\mathrm{C}$-treated infants with high and low neutralizing activities in their stools.

\begin{tabular}{|c|c|c|c|c|c|c|}
\hline \multirow[b]{3}{*}{ Treatment group } & \multirow{3}{*}{$\begin{array}{l}\text { Neutralizing } \\
\text { titer in stool }\end{array}$} & \multirow[b]{3}{*}{ No. of infants } & \multicolumn{4}{|c|}{ Duration (days) of event after hospitalization } \\
\hline & & & \multicolumn{2}{|c|}{ Diarrhea } & \multicolumn{2}{|c|}{ Excretion of virus } \\
\hline & & & Mean & $\mathrm{SE}$ & Mean & SE \\
\hline Concentrate $\mathrm{C}$ & Low & 15 & 3.13 & 0.47 & 5.00 & 0.26 \\
\hline Concentrate $\mathrm{C}$ & High & 22 & 2.54 & 0.32 & 3.36 & 0.37 \\
\hline Control & None & 43 & 3.36 & 0.33 & 5.02 & 0.29 \\
\hline
\end{tabular}

NOTE. For diarrhea, $P$ values (as determined by the Ancova test) were .378 for infants with low neutralizing titers vs. high neutralizing titers, .117 for infants with high neutralizing titers vs. controls, and .698 for infants with low neutralizing titers vs. controls. For excretion of virus, $P$ values (as determined by the Ancova test) were .007 for infants with low neutralizing titers vs. high neutralizing titers, <.001 for infants with high neutralizing titers vs. controls, and .966 for infants with low neutralizing titers vs. controls. 
trol or treatment group could not be a source of error for interpretation, we examined the following criteria. No significant differences were found for age or sex between the groups (table 3). The severity of illness, as determined by the duration of diarrhea before hospitalization and the necessity of administering parenteral fluid, was also found to be evenly distributed over the two groups of patients (table 3). Finally, an inquiry into the socioeconomic status of patients revealed no differences. In this highly industrialized region of West Germany, with a high population density (Bochum is situated near the center of the Ruhr area), the majority of parents have the social status of skilled or unskilled workers.

With regard to the problem of false-negative results in rotavirus detection by ELISA, stool samples from the critical period of transition from ELISA-positive to ELISA-negative values were independently checked by RNA gel electrophoresis or by electron microscopy or by both techniques. We disposed of the stool samples taken during these critical periods from 38 infants treated with concentrate C. In $34(89 \%)$ cases the first negative ELISA could be confirmed by a negative result by RNA gel electrophoresis and by electron microscopy. In four cases the first but not the second ELISA-negative stool samples turned out to be positive by RNA gel electrophoresis; only one of these samples was also positive by electron microscopy. Despite being negative by ELISA, all four samples were counted as positive for rotavirus in the evaluation of the clinical test.

No negative side effects were observed in the 75 infants who received the different concentrates in the three study periods.

\section{Discussion}

In this report we have demonstrated that bovine milk immunoglobulins with neutralizing-antibody activity against four human rotavirus serotypes can be used as a therapeutic agent to reduce the excretion time of rotavirus in acute rotavirus gastroenteritis in in- fants. A basic requirement for successfully treating this disease is the high-titer neutralizing activity of the milk immunoglobulin concentrates because concentrates with a less-potent activity gave negative results (table 1). The need for a high-titered antibody preparation for therapy can also be deduced from previous failures to treat rotavirus gastroenteritis with preparations that showed prophylactic activity [24, 25]. Medium-titered concentrate B may, however, also have some positive effect. A therapeutic study with concentrate B, carried out at the Children's Hospital of Philadelphia, resulted, as found in Bochum, in nonsignificant differences between the mean number of diarrheal stools per day in treated infants as opposed to control infants but in a significantly better increase in body weight in the concentrate-treated group ( $+5 \%$ on day 4 of treatment) compared with controls $(-2 \%$ on day $4, P<.001 ; H$. F. Clark and S. A. Plotkin, personal communication).

It is remarkable that orally administered heterologous antibodies can resist proteolytic degradation during gastrointestinal passage without special precautions, such as encapsulation or addition of antacid. Earlier reports from our group [37] have shown that bovine milk antibodies to $E$. coli retained their immunologic activity after gastrointestinal passage. In vitro digestion of bovine milk concentrate containing antibodies to rotavirus, as described in this paper, shows that a substantial amount of activity of neutralizing antibodies to rotavirus is still active after pepsin and trypsin treatment. This outcome is confirmed by our in vivo studies, in which quantitative comparison of ingested and recovered activity of antibody to rotavirus allowed us to conclude that $\sim 10 \%$ of the antiviral activity survived gastrointestinal passage. Similar results were reported by other authors, who showed the survival of human serum immunoglobulins after being orally administered to low-birth-weight infants [38] and the conservation of specific antitoxic activity of bovine milk immunoglobulins in in vitro and in vivo digestion trials in rabbits [39]. Our results show that orally ad-

Table 3. Characteristics of the concentrate-treated and control groups for the study period $1984-1986$.

\begin{tabular}{|c|c|c|c|c|c|}
\hline Treatment group & No. of infants & Mean age (months) & $\begin{array}{l}\text { Sex ratio, } \\
\text { male/female }\end{array}$ & $\begin{array}{l}\text { Duration (days) of diar- } \\
\text { rhea before hospitalization }\end{array}$ & $\begin{array}{l}\text { No. who received } \\
\text { perenteral fluid therapy }\end{array}$ \\
\hline Concentrate $\mathrm{C}$ & 30 & 6.9 & $20 / 10$ & 2.02 & 7 \\
\hline Control & 43 & 6.0 & $24 / 19$ & 2.03 & 7 \\
\hline
\end{tabular}


ministered antibodies can limit rotavirus replication, even after the onset of clinical symptoms. One possible explanation may be that bovine antibodies neutralize rotaviruses set free into the lumen of the intestine by infected epithelial cells. Milk immunoglobulins could thus limit, or even inhibit, further spread of the viral infection to hitherto uninfected epithelial cells or uninfected parts of the intestine.

We found appreciable amounts of neutralizing activity against human rotaviruses in the stools of concentrate $\mathrm{C}$-treated infants. Thus, treatment with milk immunoglobulin concentrate may lower the infectivity of rotavirus excreted into the stool. Unfortunately, human rotaviruses are notoriously difficult to cultivate in cell culture, and we could not therefore test this hypothesis experimentally. Nevertheless, this concentrate treatment could also have beneficial effects in limiting the potential spread of rotavirus infection in hospitals.

The decrease in the duration of diarrhea was insignificant in this study, probably for the following reasons. Because of the dietary treatment of both groups, diarrhea was of shorter duration than was excretion of virus ( 3.36 days of diarrhea vs. 5.02 days of excretion of virus in control infants). Hence, from a statistical point of view, the diarrhea criterion is not an uninfluenced, chance variable for evaluating therapeutic efficacy, as is the case with excretion of virus in control and concentrate-treated infants. Moreover, in most cases, treatment with the concentrate could only be started on the second day of hospitalization because of problems in obtaining parental consent to include their sick infant in the concentrate-treated group. Finally, by our studies on the kinetics of intestinal passage of milk immunoglobulin concentrate, we know that it took about one day to establish a milieu with neutralizing activity in the intestine. Therefore, it is conceivable that concentrate treatment started too late to influence diarrheal symptoms. Omission of dietary treatment in both groups may prolong diarrhea and thus increase the chances of observing a significant effect of the concentrate on diarrhea; however, this procedure is ethically unacceptable for control infants. We therefore decided that for the next clinical tests, we would begin treatment within $12 \mathrm{hr}$ of hospitalization.

Nevertheless, it remains remarkable that in an acute infection, viral replication can be influenced therapeutically by passively acquired antibodies, even after the onset of clinical illness.

\section{References}

1. Bishop RF, Davidson GP, Holmes IH, Ruck BJ. Virus particles in epithelial cells of duodenal mucosa from children with acute non-bacterial gastroenteritis. Lancet 1973; 2:1281-3

2. Kapikian AZ, Kim HW, Wyatt RG, Cline WL, Arrobio JO, Brandt CD, Rodriguez WJ, Sack DA, Chanock RM, Parrott RH. Human reovirus-like agent as the major pathogen associated with "winter" gastroenteritis in hospitalized infants and young children. N Engl J Med 1976;294:965-72

3. Davidson GP, Bishop RF, Townley RRW, Holmes IH, Ruck BJ. Importance of a new virus in acute sporadic enteritis in children. Lancet 1975;1:242-6

4. Middleton PJ, Szymanski MT, Petric M. Viruses associated with acute gastroenteritis in young children. Am J Dis Child 1977;131:733-7

5. Bryden AS, Davies HA, Hadley RE, Flewett TH, Morris CA, Oliver $P$. Rotavirus enteritis in the West Midlands during 1974. Lancet 1975;2:241-3

6. Kapikian AZ, Wyatt RG, Greenberg HB, Kalica AR, Kim HW, Brandt CD, Rodriguez WJ, Parrott RH, Chanock RM. Approaches to immunization of infants and young children against gastroenteritis due to rotaviruses. Rev Infect Dis 1980;2:459-69

7. Greenberg HB, Kalica AR, Wyatt RG, Jones RW, Kapikian $A Z$, Chanock RM. Rescue of noncultivatable human rotavirus by gene reassortment during mixed infection with ts mutants of a cultivatable bovine rotavirus. Proc Nat Acad Sci USA 1981;78:420-4

8. Greenberg H, Midthun K, Wyatt R, Flores J, Hoshino Y, Chanock RM, Kapikian A. Use of reassortant rotaviruses and monoclonal antibodies to make gene-coding assignments and construct rotavirus vaccine candidates. In: Chanock RM, Lerner RA, eds. Modern approaches to vaccines. Cold Spring Harbor, NY: Cold Spring Harbor Laboratory, 1984:319-27

9. Vesikari T, Isolauri E, D'Hondt E, Delem A, André FE, Zissis $G$. Protection of infants against rotavirus diarrhoea by RIT 4237 attenuated bovine rotavirus strain vaccine. Lancet 1984;1:977-81

10. Vesikari $T$, Isolauri $E$, Delem A, D'Hondt $E$, André FE, Zissis G. Immunogenicity and safety of live oral attenuated bovine rotavirus vaccine strain RIT 4237 in adults and young children. Lancet 1983;2:807-11

11. Snodgrass DR, Wells PW. Rotavirus infection in lambs: studies on passive protection. Arch Virol 1976;52:201-5

12. Snodgrass DR, Wells PW. Passive immunity in rotaviral infections. J Am Vet Med Ass 1978;173:565-8

13. Bartz CR, Conklin RH, Tunstall CB, Steele JH. Prevention of murine rotavirus infection with chicken egg yolk immunoglobulins. J Infect Dis 1980;142:439-41

14. Bridger JC, Brown JF. Development of immunity to porcine rotavirus in piglets protected from disease by bovine colostrum. Infect Immun 1981;31:906-10

15. Saif LJ, Redman DR, Smith KL, Theil KW. Passive immunity to bovine rotavirus in newborn calves fed colostrum supplements from immunized or nonimmunized cows. Infect Immun 1983;41:1118-31

16. Sheridan JF, Smith CC, Manak MM, Aurelian L. Preven- 
tion of rotavirus-induced diarrhea in neonatal mice born to dams immunized with empty capsids of simian rotavirus SA-11. J Infect Dis 1984;149:434-8

17. Offit PA, Clark HF. Protection against rotavirus-induced gastroenteritis in a murine model by passively acquired gastrointestinal but not circulating antibodies. J Virol 1985;54:58-64

18. Cushing AH, Anderson L. Diarrhea in breast-fed and nonbreast-fed infants. Pediatrics 1982;70:921-5

19. Bishop RF, Cameron DJS, Veenstra AA, Barnes GL. Diarrhea and rotavirus infection associated with differing regimens for postnatal care of newborn babies. $J$ Clin Microbiol 1979;9:525-9

20. Chrystie IL, Totterdell BM, Banatvala JE. Asymptomatic endemic rotavirus infections in the newborn. Lancet 1978; 1:1176-8

21. McLean BS, Holmes IH. Effects of antibodies, trypsin, and trypsin inhibitors on susceptibility of neonates to rotavirus infection. J Clin Microbiol 1981;13;22-9

22. Gurwith M, Wenman W, Gurwith D, Brunton J, Feltham S, Greenberg H. Diarrhea among infants and young children in Canada: a longitudinal study in three northern communities. J Infect Dis 1983;147:685-92

23. Barnes GL, Doyle LW, Hewson PH, Knoches AML, McLellan JA, Kitchen WH, Bishop RF. A randomised trial of oral gammaglobulin in low-birth-weight infants infected with rotavirus. Lancet 1982;1:1371-3

24. Ebina T, Sato A, Umezu K, Ishida N, Ohyama S, Ohizumi A, Aikawa K, Katagiri S, Katsushima N, Imai A, Kitaoka $\mathrm{S}$, Suzuki $\mathrm{H}$, Konno T. Prevention of rotavirus infection by cow colostrum containing antibody against human rotavirus. Lancet 1983;2:1029-30

25. Ebina T, Sato A, Umezu K, Ishida N, Ohyama S, Oizumi A, Aikawa K, Katagiri S, Katsushima N, Imai A, Kitaoka S, Suzuki H, Konno T. Prevention of rotavirus infection by oral administration of cow colostrum containing antihumanrotavirus antibody. Med Microbiol Immunol 1985;174:177-85

26. Hilpert H, Gerber H, Amster H, Pahud JJ, Ballabriga A, Arcalis L, Farriaux F, de Peyre E, Nussle D. Bovine milk immunoglobulins (Ig), their possible utilization in industrially prepared infant's milk formulae. In: Hambraeus $L$, Hanson LA, McFarlane H, eds. Food and Immunology. Stockholm: Swedish Nutrition Foundation, 1977:182
27. Mietens C, Keinhorst H, Hilpert H, Gerber H, Amster H, Pahud JJ. Treatment of infantile $E$. coli gastroenteritis with specific bovine anti- $E$. coli milk immunoglobulins. Eur J Pediatr 1979;132:239-52

28. Brüssow H, Hilpert $H$, Walther J, Sidoti J, Mietens C, Bachmann PA. Bovine milk immunoglobulins for passive immunization to infantile rotavirus gastroenteritis. $J$ Clin Microbiol, 1987 (in press)

29. Gerna G, Battaglia M, Milenesi G, Passarani N, Percivalle E, Cattaneo E. Serotyping of cell culture-adapted subgroup 2 human rotavirus strains by neutralization. Infect Immun 1984;43:722-9

30. Bachmann PA, Hess RG. Routine isolation and cultivation of bovine rotaviruses in cell culture. Am J Vet Res 1981;42:2149-50

31. Brüssow H, Marc-Martin S, Eichhorn W, Sidoti J, Fryder V. Biochemical characterization of a second serotype of bovine rotavirus. Arch Virol 1987 (in press)

32. Wyatt RG, Greenberg HB, James WD, Pittman AL, Kalica AR, Flores J, Chanock RM, Kapikian AZ. Definition of human rotavirus serotypes by plaque reduction assay. Infect Immun 1982;37:110-5

33. Ouchterlony Ö. Antigen-antibody reactions in gels. Acta Pathol Microbiol Scand 1949;26:507-15

34. Scheidegger JJ. Une micro-méthode de l'immunoélectrophorèse. Int Arch Allergy 1955;7:103-110

35. de Rham O, Isliker H. Proteolysis of bovine immunoglobulins. Int Arch Allergy Appl Immun 1977;55:61-9

36. Fang WD, Mukkur TKS. Physicochemical characterization of proteolytic cleavage fragments of bovine colostral immunoglobulin $G_{2}\left(I g G_{1}\right)$. Biochem J 1976;155:25-30

37. Hilpert H, Gerber H, de Peyer E, Nusslé D. Gastrointestinal passage of bovine anti-E. coli milk immunoglobulins $(\mathrm{Ig})$ in infants. Nestlé Research News 1974/75:134-8

38. Blum PM, Phelps DL, Ank BJ, Krantman HJ, Stiehm ER. Survival of oral human immune serum globulin in the gastrointestinal tract of low birth weight infants. Pediatr Res 1981;15:1256-60

39. McClead RE, Gregory SA. Resistance of bovine colostral anti-cholera toxin antibody to in vitro and in vivo proteolysis. Infect Immun 1984;44:474-8 